\title{
Help-giving and moral courage on the Internet
}

\author{
Suna P. Kinnunen ${ }^{1}$, Marjaana Lindeman², Markku Verkasalo ${ }^{3}$ \\ ${ }^{1}$ University of Helsinki, Helsinki, Finland \& Johann Wolfgang Goethe University, Frankfurt am Main, Germany \\ 2,3 University of Helsinki, Helsinki, Finland
}

\begin{abstract}
The study addressed individual differences on two types of prosocial behavior on the Internet: helpgiving/sharing and moral courage. A questionnaire to measure these behaviors was developed. We investigated the effects of the Big Five personality traits, sadistic traits, and values on help-giving and moral courage. We found that the willingness to help on the Internet was promoted by open personality, and the relationship was partly moderated by high weekly use of social media. The willingness to act morally courageous was promoted by open personality, inclination toward sadism, and self-transcendence values. Surprisingly, the relationship between moral courage and sadistic traits was not moderated by the time spent online. Willingness to donate to a charity was fostered by benevolence and universalism values. Future studies will need to replicate the results with behavioral observations.
\end{abstract}

Keywords: Moral courage; helping; Internet; personality; values; sadism

\section{Introduction}

Other-regarding behavior is one of the most important everyday virtues, and even though the Internet is very much a part of our everyday life, prosociality on the Internet is poorly understood. In real-life, the helper is identified, the principle of reciprocity is a value, and social pressure and the presence of other potential helpers can both promote and discourage helping (Latané \& Darley, 1968; Pöyhönen, Juvonen, \& Salmivalli, 2012; Thornberg, 2007). On the Internet, the situation is different as interaction is often anonymous and social presence is not evident. However, there are links between online and offline behavior and studies on prosocial behavior have found that face-to-face prosocial behaviors are positively associated with positive online behavior (Wright \& Li, 2011).

It is possible to act prosocially on the Internet in several ways, for example, by contributing to various services (e.g., Wikipedia or Linux), by forwarding content, posting links and watching videos to support a cause (e.g., causes.com), and by clicking to donate, (e.g., care2.com, sharewood.org). While large body of research has focused on negative interactions and cyberbullying on the Internet (see, e.g., Calvete, Orue, Estévez, Villardón, \& Padilla, 2010), very little is known about prosocial behavior online, particularly when this behavior is not limited to social-media interactions with friends and family (Correa, Hinsley, \& De Zúñiga, 2010) or gaming societies (e.g., Ang \& Zaphiris, 2010; Wang \& Wang, 2008). While prosocial behavior can encompass a large variety of otherregarding actions, in this study we focus on help-giving and moral courage: Two other-benefiting behaviors that are costly to the actor and have been in previous research suggested to be facets of a more general altruism construct (Kinnunen, Singh, \& Windmann, 2015; Kinnunen \& Windmann, 2013). We will examine how individual 
differences, namely personality traits and values, predict these prosocial behaviors on the Internet in a wide social context, i.e., interactions with anonymous others and people other than friends and family.

\section{Help-Giving and Moral Courage}

When considering interaction with people outside one's immediate social environment (i.e., friends and family), the most often mentioned motivator of sharing and helping is empathy (e.g., Batson, 1991; Dickert, Sagara, \& Slovic, 2011), and it is thought to be supported by and serves to maintain positive affect (Stel, Van Baaren, \& Vonk, 2008). Other studies have shown altruism, unselfish interest of helping others, to be one motive behind other-benefiting activities (see Bekkers \& Wiepking, 2010, for meta-analysis; online: Klisanin, 2011; Utz, 2009). Even when the social effects of reputation building and reciprocity are minimized, helping others can yield benefits for the helper. For example, voluntary help-giving is related to greater subjective well-being, vitality, and self-esteem (Weinstein \& Ryan, 2010), and can result in satisfaction of fulfilling the self-image of helpfulness (see Bekkers \& Wiepking, 2010, for meta-analysis). On the Internet, help-giving can include donating money or time to a cause and sharing thoughts, knowledge, and experiences on social networks and discussion forums (see, e.g., Rudolph, Roesch, Greitemeyer, \& Weiner, 2004, for a review; Rushton, Chrisjohn, \& Fekken, 1981).

Moral courage manifests as a willingness to take action in situations that conflict with person's moral or sense of what is just (see, e.g., Lodge \& Frydenberg, 2005; Poteat \& Vecho, 2016). This usually implies risking threats, humiliation, loss of social status, or verbal or even physical abuse by taking a stand against, for example, discrimination based on race or religiosity. Empirical research on moral courage has been published in the context of the medical profession (e.g., Bickhoff, Sinclair, \& Levett-Jones, 2015) and business ethics (e.g., Sekerka, Bagozzi, \& Charnigo, 2009). The few studies on moral courage in the field of psychology have found that justice sensibility, moral mandates, anger (anger: Halmburger, Baumert, \& Schmitt, 2015; Kayser, Greitemeyer, Fischer, \& Frey, 2010), and reflective thinking style (Kinnunen \& Windmann, 2013) are related to moral courage. Another study has established that moral disengagement, self-efficacy, and social anxiety are related to moral intentions, while taking morally courageous action is predicted by beneficiary sensitivity (Baumert, Halmburger, \& Schmitt, 2013). To our knowledge, no research has focused on moral courage on the Internet, even though the Internet is an important media for such direct-action organizations as Amnesty International and Greenpeace, for collecting signatures for citizens' initiatives, and for cyberbullying and its prevention. In particular, cyberbullying is increasing with the accessibility and high usage of social-media technology among adolescents and school-aged children (Calvete et al., 2010; Rigby \& Smith, 2011), and it can be even more appealing than real-life bullying as it can be done anonymously (Sticca \& Perren, 2013).

\section{Individual Differences and Prosocial Behavior on the Internet}

Personality traits describe people in terms of stable patterns of behavior, thoughts, and emotions, (see, e.g., McCrae \& Costa, 2003). Earlier studies have shown that positive emotionality (Krueger, Hicks, \& McGue, 2001), openness (Ben-Ner, Kong, \& Putterman, 2004), neuroticism, low conscientiousness and low agreeableness (BenNer \& Kramer, 2011), as well as agreeableness and extraversion (Bekkers, 2006; Elshaug \& Metzer, 2001; see also Carlo, Okun, Knight, \& de Guzman, 2005), among others, predict helping behavior in everyday life. In addition, extraversion and openness to experience are positively related to social-media use (Correa et al., 2010). However, these studies have focused on giving and volunteering in real-life, in monetary games, or overall usage of social-media, and little is known about how personality differences relate to the willingness to take punitive or morally courageous action or to the willingness to help or share online. Based on the above findings, we expect that openness, high neuroticism, and extraversion promote help-giving online, and that neuroticism, conscientiousness, and extraversion promote moral courage online.

Big Five is a taxonomy of personality traits that is derived from people's descriptions of themselves and others (see, e.g., John, Naumann, \& Soto, 2008, for a review). However, it does not fully capture the darker side of personality, and concerns have been raised that the existing approaches are overly narrow (Jackson \& Poulsen, 2005) and that additional personality variables, the darker traits in particular, could be significant overlooked factors (Hodson, Hogg, \& McInnis, 2009). Indeed, research interest for more noxious personality traits has increased in recent years, and studies have found main effects for darker traits even after controlling for Big Five variation (e.g., Böckler, Sharifi, Kanske, Dziobek, \& Singer, 2017; Buckels \& Paulhus, 2013; Buckels, Trapnell, \& 
Paulhus, 2014; Greitemeyer, 2015). Thus, we include sadistic traits to our study in order to get a more complete understanding of individual differences and prosocial behavior on the Internet. More noxious traits could contribute to prosocial behavior online because sadistic, psychopathic, narcissistic, and Machiavellian traits are positively associated with the time spent commenting on various websites (Buckels et al., 2014). These associations support the idea that noxious personality traits contribute to commenting on social media, and thus, by providing information, these traits may also promote sharing and helping behavior-even if the motivation of the individual is not very other-regarding. A recent study indicates that high narcissism is related to low generosity and high punishing or retaliation behavior (Böckler et al., 2017). The relationship between narcissism and retaliation is partly driven by anger, which is also a motivator behind morally courageous behavior (see, e.g., Halmburger et al., 2015; Kayser et al., 2010). Furthermore, violent video gaming, a behavior related to sadistic traits (Buckels \& Paulhus, 2013; Greitemeyer, 2015), is suggested to decrease empathy and prosocial behaviour (Anderson et al., 2010). Thus we expect that dark personality traits are related to low helpgiving but high moral-courage on the Internet.

The second domain of individual differences focused on in this study is that concerning values. Values and personality traits are different kinds of concepts that refer to different aspects of personality in that traits constitute the stylistic context for the expression of values and other motivational beliefs (Bilsky \& Schwartz, 1994; Schwartz \& Bilsky, 1990; Winter, John, Stewart, Klohnen, \& Duncan, 1998). In other words, personality traits channel the ways in which people express their values. Accordingly, a recent meta-analysis shows that traits and values are distinct constructs and that while there are theoretically meaningful relationships between personality traits and basic values, these relationships are not generally large (Parks-Leduc, Feldman, \& Bardi, 2014). Because these two constructs, although conceptually and empirically distinct, are systematically related and can mutually influence one another (Roccas, Sagiv, Schwartz, \& Knafo, 2002), and because both traits and values have in previous literature successfully predicted various behaviors and attitudes (values and behavior: Bardi \& Schwartz, 2003; values and prosocial behavior: e.g., Schwartz, 2010; traits: e.g., Ben-Ner \& Kramer, 2011; Correa et al., 2010; Krueger et al., 2001), we include values as the second domain of individual differences in this study.

As values are the basis of how we decide to behave, they are important when considering prosocial behavior. Indeed, internalized moral value, a moral principle to care for others, promotes charitable giving (Bekkers \& Ottoni-Wilhelm, 2016). Volunteerism in real-life and social cooperation in games have been found to be associated with prosocial values, such as universalism and benevolence (Hobfoll, 1980; Sagiv, Sverdlik, \& Schwarz, 2011). According to Schwartz's theory of values (Schwartz, 1992), universalism and benevolence are self-transcendence values. We thus expect that self-transcendence values promote moral courage and helpgiving, which require a concern for others' well-being. In addition, openness to change values are expected to promote help-giving and moral courage as they require a willingness to change and independent thought and action.

\section{The Present Study}

In this study we address the question, how personality traits and values relate to the willingness to engage in prosocial behavior online? Because online help-giving and morally courageous action take place in social-media and other Internet platforms, it is important to investigate how active Internet and social-media use moderate the possible effects of individual differences on these prosocial behaviors online. Thus, we also address the question, whether the relationships between individual differences and prosocial behavior online are moderated by internet or social-media use? We anticipate that the personality traits high openness, extraversion, and neuroticism will promote help-giving/sharing (Hypothesis 1), and high neuroticism, extraversion and conscientiousness will promote moral courage (Hypothesis 2). We also expect high sadistic traits to decrease help-giving and promote moral courage (Hypothesis 3). Finally, we expect that high self-transcendence values foster moral courage, help-giving and donating (Hypothesis 4), and that high openness to change values endorse moral courage (Hypothesis 5). 


\section{Method}

\section{Pilot Study}

Participants were recruited through Helsinki University's email lists ( $N=45$, age range 19-47 years, 34 women). Of the participants $89 \%$ were psychology students. To develop the Online Prosocial Scale (OPS), the participants were asked what type of behavior they consider to be altruistic or morally courageous on the Internet. The text presented to the participants read as follows: "Altruism is other-benefiting behavior that does not benefit the actor him-/herself. 1) In your opinion, what type of behavior on the Internet is help-giving? Mention at least two. 2) Moral courage is courage to speak up or act according to one's moral and sense of what is just in situations that are threatening and can be harmful to the actor. In your opinion, what type of behavior on the Internet depicts moral courage? Mention at least two."

To the question of what type of behavior on the Internet is altruistic, the most common answers included answering other people's questions, sharing knowledge, answering surveys, and sharing one's own experiences, for example regarding a hotel, other service, or a product (17 of 36 answers). In the answers to the question of what type of behavior on the Internet reflects moral courage, the most common themes included stating one's own opinion when it differs from or opposes a commonly held opinion and defending those who have been oppressed or bullied (20 of 34 answers). Anonymity was valued in altruistic sharing or helping behavior, while revealing one's identity was a common requirement for a morally courageous action. The most common answers were utilized to develop items in the OPS.

The participants were also asked to estimate on a scale of $0,1,2,5,10,20, \ldots, 100$ Euro how valuable an Amazon voucher they would exchange for a donation of the same value to a charity of their choosing. Half of the participants reported to choose a donation when the voucher was for 20 Euro or less, $M d n=20 €, M=34.44 €$, $S D=31.52 €$. An opportunity to exchange a $20 €$ Amazon voucher for a charity donation was used as a measure of willingness to donate in the main study.

\section{The Main Study}

Participants. Participants ( $N=352$, mean age $=25.66$ years, range 18-44 years, 260 women) were recruited via student email lists of five Finnish Universities during May 2014 and January 2015. The participants were students of three study areas: 1$)$ Health, social, educational, and behavioral sciences $(n=123), 2)$ Humanistics $(n=158)$, and 3) Technical and natural sciences $(n=71)$.

\section{Measures.}

The time spent online were asked separately for Internet use in general and for online communities and services in particular. Of the participants 59\% spent over 16 hours per week online (range from 1.5 to over 16 hours). Half of the participants spent weekly less than six hours on online communities, such as Facebook, Twitter, blogs and discussion forums. Less than four hours were spent on free Internet services such as Youtube, Wikipedia, and Flickr (range from less than half an hour to over 16 hours).

The 23-item Online Prosocial Scale consisted of two sub-scales, help-giving (HG, 13 items) and moral courage (MC, 10 items). The participants were asked to evaluate how well each item described themselves ( $1=$ not at all to $6=$ describes very well, $7=$ have not encountered this situation). The questionnaire was constructed in Finnish. The reliability (Cronbach's $\alpha$ ) of the Online Prosocial Scale subscales were high, HG: $a=.89$; MC: $a=.91$.

Fundamental personality traits were assessed with the Finnish version of the Short Five questionnaire (S5; Konstabel, Lönnqvist, Walkowitz, Konstabel, \& Verkasalo, 2012). The S5 is a 60-item questionnaire where five personality traits are represented by 12 items each. The respondents evaluate each item (e.g., "It is easy for me to resist temptation; I can always control my feelings and desires") in terms of how well it describes themselves ($3=$ The description is completely wrong $-3=$ The description is completely correct). The reliabilities in this sample were satisfactory: Neuroticism $a=.84$; Extraversion $a=.80$; Openness $a=.66$; Agreeableness $a=.54$; and Conscientiousness $a=.73$. 
Sadism was assessed with the 18-item Comprehensive Assessment of Sadistic Tendencies (CAST; Buckels \& Paulhus, 2013; in this sample $a=.79$ ). Filler items were intermixed to offset negativity. The items (e.g., "I enjoy physically harming people") were rated on a five-point scale $(1=$ Strongly disagree to $5=$ Strongly agree $)$. The questionnaire was translated by a native Finnish speaker and checked by another.

Personal values were assessed with the Finnish version of the 21-item Portrait Values Questionnaire (PVQ-21; Schwartz et al., 2001). The items describe different people, their goals and views in two sentences (e.g., "It is important to her to show her abilities. She wants people to admire what she does"), and the participants are asked to evaluate "how much like you is this person" ( 1 = very much like me to $6=$ not like me at all). The 10 basic values are organized on two-value axis as follows: Self-transcendence values (universalism and benevolence) are opposed to self-enhancement values (achievement and power), and conservation values (conformity, tradition, and security) are opposed to openness to change values (self-direction and stimulation) (Schwartz, 1992; Verkasalo, Lönnqvist, Lipsanen, \& Helkama, 2009). The scores were transformed by using the weights provided by Verkasalo et al. (2009).

Procedure. The participants completed the measures on an online survey open for a two weeks period in the following order: demographic variables and time spent online, OPS, S5, CAST, and PVQ-21. Next, the participants were asked for their email address in order to participate in a lottery. In the lottery they could win a 20 Euro Amazon voucher or donate the sum to a charity of their own choice. As compensation, the participants were offered the opportunity to download their own PVQ-21 value profile.

\section{Results}

\section{Development of the Online Prosocial Scale}

Thirty-two items about prosocial behavior online were presented to the participants. The value 7 (have not encountered this situation) provided information on how typical the described situations were and was treated as a missing value in the analyses. The items were entered into exploratory factor analysis using the maximum likelihood solution. The factor model was then rotated Varimax rotation. All items that had primary loadings lower than .40 or cross-loadings larger than .30 were excluded. The final factor solution with 23 items is presented in Table 1. Mean sum variables were formed and used in the following analyses, $H G: M=1.97, S D=$ $0.80, M n d=1.85$, Rng = 1.00-4.85; MC: $M=2.37, S D=1.15, M n d=2.10$, Rng = 1.00-6.00.

\section{Differences Between the Prosocial Behaviors}

Because the distributions of help-giving and moral courage scores differed significantly from normal, nonparametric analyses or logarithmic transformations were used when appropriate. First, differences between the willingness to engage in help-giving and morally courageous behavior were compared using paired samples Wilcoxon Signed Rank test. Help-giving was estimated less frequent activity than moral courage, $Z=-4.08, p<$ .001. Next, willingness to donate to charity was analyzed. Those who were willing to donate scored higher on the moral courage subscale, MC: $U=2704.00, p<.001$. Similar trend was also found when comparing donating with help-giving, HG: $U=1922.00, p=.076$. In addition, agreeing with our Hypothesis 4, those who valued universalism and benevolence were also likely to give their winnings to a charity, $M=.18, S D=.38, U=5168.50, p$ $<.001, r b=.63$.

Correlational analyses were conducted next (Table 2). Extraversion was not related to the prosocial behaviors, all $p^{\prime} s>$.12. Help-giving was connected to high sadistic traits and open personality. Moral courage was connected to open personality, low conservation values, sadistic traits, and neuroticism. Thus, Hypotheses 1 and 2 were partly supported, the Hypothesis 5 was supported, and the Hypothesis 4 about the self-transcendence values did not receive support. 


\section{Subscale}

Help- $\quad$ Moral $h^{2}$

\section{Help-giving}

1 I use web-sites that generate donations to charities, such as click-to-donate

fundraising platforms

2 I use internet lottery-sites, where the winnings are donated to charities

3 I actively answer other users' questions on the internet

.43

4 I actively help people with their problems with, for example, equipment, programs, or software.

5 I often share my experiences on products or services on the Internet (e.g., on discussion forums or social media)

6 I actively help people to find information on the Internet

7 I anonymously and sincerely help people on social media, such as on Internet discussion forums

8 I advise others on how to make or fix things (such as DIY, baking, or crafting)

9 I often share information on my hobbies or on things in which I am skilled

10 I contribute to free information services, such as Wikipedia, by editing and writing content

11 I often donate money for the upkeep of free information services (such as Wikipedia, Youtube, Vlogaajat)

12 I contribute content to free services (such as recording for Librivox, digitalizing books for the Gutenberg project)

13 I comment anonymously on other people's blog entries in a positive way

\section{Moral courage}

14 I actively take part in action that tries to influence moral issues by, for example, signing petitions and appeals on the internet

15 I have signed petitions that try to influence contemporary moral and ethical issues, such as discrimination based on ethnicity or sexual orientation, child abuse, environmental concerns, or animal rights

16 I have shared material, such as links or videos, concerning human rights, child rights, environmental concerns, or animal rights on the Internet

17 I have asked others to sign petitions that try to influence contemporary moral and ethical issues

18 I have criticized a company or a nation that violates human rights, environmental laws, or animal rights on the Internet

19 I have asked others on the Internet not to use products or services provided by a company that violates human rights, environmental laws, or animal rights

20 I have expressed on the Internet my untypical moral opinion under my own name

21 I have declared on the internet (e.g., on my blog or Facebook page) that I

\section{oppose a social injustice, such as the non-legalization of same-sex marriages}

22 I have published a picture of a criminal on my Internet-page (e.g., on my blog or 
Table 2. Correlations Between the variables. Only Variables Correlating Significantly with One or Both of the Prosocial Variables Are Included in the Table.

\begin{tabular}{|c|c|c|c|c|c|c|c|c|c|c|c|}
\hline & MC & $\mathbf{N}$ & $E$ & 0 & A & C & CAST & $\begin{array}{l}\text { Conser- } \\
\text { vation }\end{array}$ & $\begin{array}{l}\text { Self- } \\
\text { transce } \\
\text { ndence }\end{array}$ & $\begin{array}{l}\text { Internet } \\
\text { use }\end{array}$ & $\begin{array}{c}\text { Social- } \\
\text { media } \\
\text { use }\end{array}$ \\
\hline HG & $.45^{\star \star \star}$ & .09 & .05 & $.21^{\star \star}$ & -.06 & -.03 & $.21^{* *}$ & .06 & -.00 & $.21^{\star *}$ & $.31^{* \star *}$ \\
\hline $\mathrm{MC}$ & & $.19^{* *}$ & -.00 & $.34^{* \star \star}$ & -.07 & -.09 & $.21^{* *}$ & $-.23^{\star \star *}$ & .11 & $.19^{* *}$ & $.26^{* * *}$ \\
\hline $\mathrm{N}$ & & & $-.47^{\star \star \star}$ & -.03 & $-.17^{\star \star}$ & $-.42^{\star \star \star}$ & .05 & $.15^{* \star}$ & .02 & $.17^{* *}$ & $.15^{* \star}$ \\
\hline E & & & & $.33^{* * *}$ & $.20^{* * *}$ & $.26^{* * *}$ & -.01 & $-.43^{* * *}$ & .06 & $-.18^{* *}$ & -.04 \\
\hline 0 & & & & & $.25^{* * *}$ & .06 & .00 & $-.61^{* * *}$ & $.31^{* * *}$ & $-.18^{* *}$ & -.04 \\
\hline A & & & & & & $.18^{* *}$ & $-.43^{* \star *}$ & $-.11^{*}$ & $.53^{* * *}$ & -.03 & -.07 \\
\hline C & & & & & & & $-.14^{\star \star \star}$ & .08 & .01 & $-.25^{\star \star \star}$ & $-.27^{\star \star \star}$ \\
\hline CAST & & & & & & & & $-.13^{*}$ & $-.30^{\star \star \star}$ & .10 & $.14^{* *}$ \\
\hline Cons. & & & & & & & & & $-.24^{\star \star \star}$ & -.02 & -.02 \\
\hline Self-t. & & & & & & & & & & .01 & -.04 \\
\hline Int. & & & & & & & & & & & $.51^{* * *}$ \\
\hline
\end{tabular}

Note: ${ }^{* * *} p<.001 ;{ }^{* *} p<.01 ;{ }^{*} p<.05 . \mathrm{HG}=$ help-giving, $\mathrm{MC}=$ moral courage, $\mathrm{N}=$ neuroticism, $\mathrm{E}=$ Extraversion, $\mathrm{O}=$ openness, $\mathrm{A}=$

agreeableness, $\mathrm{C}=$ conscientiousness, CAST $=$ comprehensive assessment of sadistical tendencies .

Table 3. Regression analyses for help-giving and moral courage.

\begin{tabular}{|c|c|c|c|c|}
\hline Dependent variable & Independent variable & $\beta$ & $t$ & $p$ \\
\hline \multirow[t]{14}{*}{ Help-giving } & Openness & .30 & 2.96 & .004 \\
\hline & Neuroticism & .15 & 1.46 & .147 \\
\hline & Extraversion & .10 & 1.03 & .305 \\
\hline & Conscientiousness & .09 & 0.83 & .406 \\
\hline & Agreeableness & -.14 & -1.29 & .199 \\
\hline & CAST & .10 & 1.09 & .278 \\
\hline & Conservation & .13 & 1.19 & .237 \\
\hline & Self-transcendence & .08 & 0.82 & .411 \\
\hline & Internet use & .17 & 1.14 & .258 \\
\hline & Social-media use & .10 & 0.79 & .431 \\
\hline & Internet use $x$ Extraversion & .22 & 1.92 & .057 \\
\hline & Social-media x Openness & .33 & 0.25 & .013 \\
\hline & Social-media x Extraversion & -.30 & -2.61 & .010 \\
\hline & $F(27,128)=2.37, p=.001, R^{2}=.33$, adj. $R^{2}=.19$ & & & \\
\hline \multirow[t]{11}{*}{ Moral courage } & Openness & .28 & 3.12 & .002 \\
\hline & Neuroticism & .15 & 1.73 & .086 \\
\hline & Extraversion & -.05 & -0.52 & .605 \\
\hline & Conscientiousness & .06 & 0.68 & .499 \\
\hline & Agreeableness & -.04 & -0.51 & .610 \\
\hline & CAST & .27 & 3.32 & .001 \\
\hline & Conservation & -.07 & -0.77 & .443 \\
\hline & Self-transcendence & .20 & 2.41 & .017 \\
\hline & Internet use & .01 & 0.12 & .903 \\
\hline & Social-media use & .11 & 1.20 & .232 \\
\hline & $F(27,180)=2.68, p<.001, R^{2}=.29$, adj. $R^{2}=.18$ & & & \\
\hline
\end{tabular}

Note: CAST = comprehensive assessment of sadistic tendencies; VIF for all independent variables $<2.53$; for all interactions $<$ 3.79. 
To analyze unique effects of the associated individual differences on the two other-regarding behaviors, regression analyses were conducted. In order to examine the possible moderation effect, we included interactions of Internet and social-media use and the variables measuring individual differences into both models. The results are presented in Table 3. For readability and to save space, only interactions with significance above .100 were included in Table 3. Logarithmically transformed help-giving $(M=0.60, S D=0.39)$ was predicted by open personality and the interactions of social-media and open personality and social-media and extraversion. The residual of the model agreed with normal distribution, $K-S(156)=.07, p=.066$. Logarithmically transformed moral courage $(M=0.75, S D=0.47)$ was significantly predicted by open personality, sadistic traits, and self-transcendence values. The residual of the model agreed with normal distribution, $K-S(208)$ $=.05, p>.200$.

To investigate the interactions between social-media use and the personality traits Openness and Extraversion, slope analyses were conducted and visualizations of the interactions are presented in Figure 1. The slope tests show that social-media use seems to moderate the effect of openness on help-giving on the Internet, $t(128)=$ 3.26, $p=.001$. As the main effect of Openness indicates (see Table 3), people with open personality are more likely to help on the Internet and this relationship is stronger with active compared to less active social-media users. The interaction of social-media use and extraversion seems to suggest that active social-media users are more likely to give help on the Internet if they are low compared to high on extraversion. However, this relationship was not significant when the slope was tested, $t(128)=0.28, p=.772$.
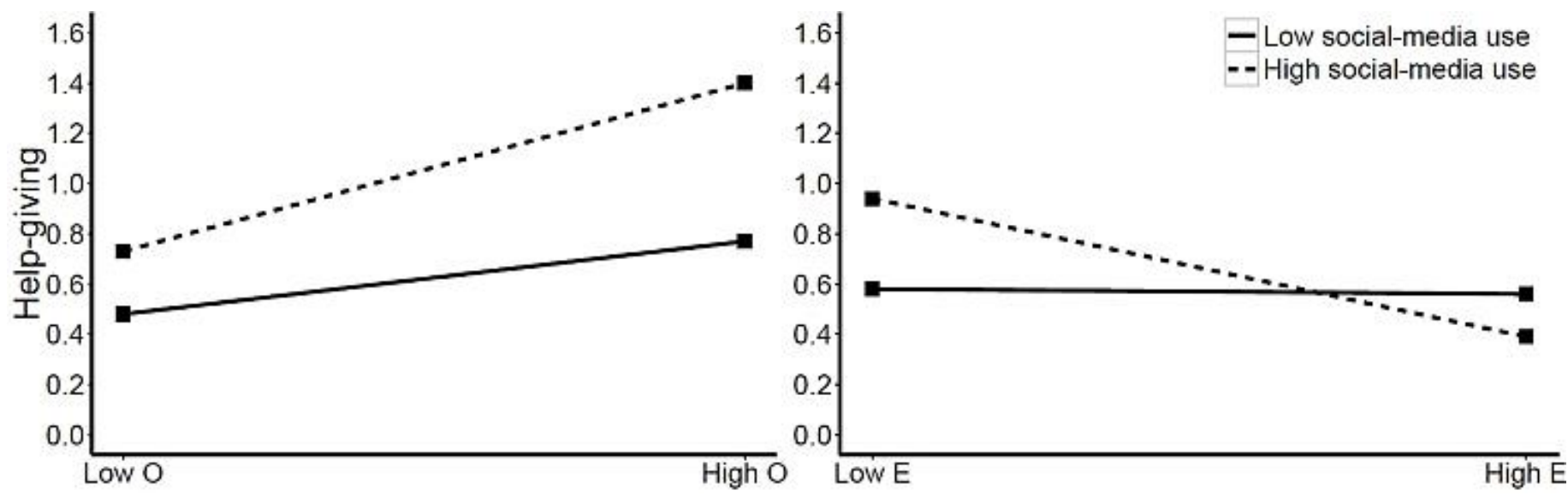

Figure 1. On the left, the interaction of social-media use and openness $(0)$ personality trait. On the right, the interaction of social-media use and extraversion (E) personality trait. The $y$-axis shows the willingness to give help on the Internet.

\section{Discussion}

The results demonstrate that Big Five, more noxious personality traits, and personal values contribute to the willingness to engage in prosocial behavior online. Internet and social-media use had no moderating effects with the exception of high social-media use strengthening the relationship between openness and help-giving on the Internet.

Help-giving and moral courage were multiply determined. Firstly, help-giving and moral courage were supported by open personality, which is in line with previous research on help-giving offline (Ben-Ner et al., 2004; Dawes, Fowler, Johnson, McElreath, \& Smirnov, 2007). This finding indicates that people who are generally curious, open to emotions, and willing to try new things are help-giving and morally courageous both in real-life and on the Internet. Previous research indicates that people with open personality are active instant message and socialmedia platform users (Correa et al., 2010), which agrees with our result of the mediating effect of social-media use on the relationship between help-giving and openness: In addition to its unique effect, open personality was more strongly connected to help-giving for active compared to less active social-media users. This is interesting 
because contrary to real-life helping situations, help-giving on the Internet is less interactive: The person giving help often receive no indication whether the information or material they provided was in fact taken in by the person or group they intended to help, or anyone else for the matter.

Secondly, participants with sadistic inclinations saw themselves more willing to take morally courageous action online when witnessing injustice than the other participants. This effect was not moderated by Internet or socialmedia use. Earlier studies have shown that enjoyment of hurting or dominating others is associated with debating important issues on web-sites (Buckels et al., 2014). It could be that individuals with sadistic traits are more involved on Internet communities and, for self-assertion and self-enhancement, answer more readily others' questions, take part on debates, and criticize others. Indeed, classically sadists have thought to seek powerful social positions enabling them to exercise their need for control and dole out punishments or humiliation (see, e.g., Myers, Burket, \& Husted, 2006). The relationship between dark personality traits and moral courage agrees with previous research suggesting that narcissism promotes punishing or retaliation behavior (Böckler et al., 2017). People with sadistic traits can be more willing to take action when witnessing injustice compared to those with low trait sadism. Earlier studies have demonstrated a connection between anger and morally courageous behavior (Halmburger et al., 2015; Kayser et al., 2010). Furthermore, anger is a driver between narcissism and retaliation (Böckler et al., 2017). Together this could suggest that the sadistic traits promoting morally courageous behavior on the Internet could be mediated by the feeling of anger. It remains for future studies to establish, whether such mediation exists. The information read on the Internet is interpreted by the receiver in the frame of mind they are at that moment and because of the lack of intonations and other paralinguistic cues, even in sarcastic or in hostile state of mind written messages may benefit others (Kruger, Epley, Parker, \& Ng, 2005). The result indicates that sadistic inclination, a trait that is generally considered undesirable and even destructive, could have productive and coopearative effects on the Internet. This result further supports the idea that a wider view of personality, one that encompasses not only traditional but also sub-clinical variation of more noxious personality traits, could be beneficial and broaden our understanding of social behavior both on- and off-line (see, e.g., Buckels et al., 2014; Greitemeyer, 2015; Jackson \& Poulsen, 2005).

In addition to openness and sadistic traits, the willingness to act morally courageous was promoted by selftranscendence values. A previous study found that openness to experience is related to the self-transcendence value universalism (Roccas et al., 2002), and our findings show that they both contribute to the willingness to take morally courageous action. Agreeing with previous research on volunteerism in real-life and social cooperation in games (Hobfoll, 1980; Sagiv et al., 2011), this suggests that people who value understanding, appreciation, tolerance, and enhancing the well-fare of people and nature are willing take morally courageous action on the Internet. Moral courage was also more likely behavior to be engaged online compared to helpgiving. This result is important considering the high social-media usage of adolescents and school-aged children, and the transmutation of bullying to the Internet, in particular (e.g., Patchin \& Hinduja, 2006).

Besides self-reports, we asked the participants whether they would be ready to donate 20 Euros to a charity of their own choosing. Those willing to donate also evaluated themselves helpful and morally courageous. Although self-transcendence values were not connected to help-giving, they promoted the donating of money to a charity. Donating on the Internet seems thus to be connected to the same values as helping behavior in reallife (e.g., Dawes et al., 2007). Only $18 \%$ of the participants chose to donate. Previous studies with a non-obvious option to give to a charity have found a high percentage (30-45\%) but a low value (less than a dollar or an euro) of the donations (Blaszczynski, Gainsbury, \& Karlov, 2014; Kinnunen \& Windmann, 2013). The relatively low percentage in the current study is surprising since the value of the Amazon voucher was determined by a pilotstudy and there was no reputation bias of the charity as the participants were free to choose any charity they desired to donate to. It seems that people estimate themselves more giving or sharing than they actually are when facing a real choice to donate.

There were some limitations in this study. Most of the data were from self-report assessments and the participants were recruited via email lists of Finnish Universities and thus the sample represents a limited age range and level of education. The online prosocial scale introduced in this study is the first attempt to survey 
prosocial behavior on the Internet and further research, particularly employing behavioral measures, is needed to confirm its validity. In addition, applying OPS into real-life situations could explore the question are there real differences between on- and offline prosocial behavior. Cross-cultural studies would be important to understand cultural implications for individual differences on online prosocial behavior. Particularly, studies comparing liberal cultures and countries with the ones where the liberty of speech is limited and the governmental supervision is stronger (see, e.g., www.worldaudit.org), would be informative. In such countries, voicing one's opinions against mainstream and standing against moral injustice could result harsher repercussions compared to more liberal countries.

In sum, the results suggest that very different characteristics, namely universalism and benevolence values, open personality, and sadistic traits predict prosocial view of oneself on the Internet. Surprisingly, the results indicate that sadism, a personality trait that is typically associated with undesirable behavior, may be beneficial and have positive outcomes on the Internet where social interactions are generally indirect and can be anonymous. More interestingly, the effect of sadistic personality traits on the willingness to engage in morally courageous behavior was not moderated by the time spent on the Internet. The results of this study imply that additional personality traits, specifically darker traits, could be overlooked predictors in social behavior, and that a more complete understanding of how individual differences relate to behavior could be achieved by focusing on both personality traits and values. As some studies have demonstrated a connection between social behavior in real-life and on the Internet (e.g., Wright \& Li, 2011) and the prosocial behaviors investigated in this study are partly promoted by the same individual characteristics as help-giving in real-life, future research could investigate whether sadistic traits and basic human values are connected to moral-courage in off-line situations as well.

\section{References}

Anderson, C. A., Shibuya, A., Ihori, N., Swing, E. L., Bushman, B. J., Sakamoto, A., .. Saleem, M. (2010). Violent video game effects on aggression, empathy, and prosocial behavior in eastern and western countries: A metaanalytic review. Psychological Bulletin, 136, 151. http://dx.doi.org/10.1037/a0018251

Ang, C. S., \& Zaphiris, P. (2010). Social roles of players in MMORPG guilds: A social network analytic perspective. Information, Communication \& Society, 13, 592-614. http://dx.doi.org/10.1080/13691180903266952

Bardi, A., \& Schwartz, S. H. (2003). Values and behavior: Strength and structure of relations. Personality and Social Psychology Bulletin, 29, 1207-1220. http://dx.doi.org/10.1177/0146167203254602

Batson, C. D. (1991). The altruism question: Toward a social-psychological answer. Hillsdale, NJ: Erlbaum.

Baumert, A., Halmburger, A., \& Schmitt, M. (2013). Interventions against norm violations dispositional determinants of self-reported and real moral courage. Personality and Social Psychology Bulletin, 29, 1053-1068. http://dx.doi.org/10.1177/0146167213490032

Bekkers, R. (2006). Traditional and health-related philanthropy: The role of resources and personality. Social Psychology Quarterly, 69, 349-366. http://dx.doi.org/10.1177/019027250606900404

Bekkers, R., \& Ottoni-Wilhelm, M. (2016). Principle of care and giving to help people in need. European Journal of Personality, 30, 240-257. http://dx.doi.org/10.1002/per.2057

Bekkers, R., \& Wiepking, P. (2010). A literature review of empirical studies of philanthropy: Eight mechanisms that drive charitable giving. Nonprofit and Voluntary Sector Quarterly, 40, 924-973.

http://dx.doi.org/10.1177/0899764010380927

Ben-Ner, A., Kong, F., \& Putterman, L. (2004). Share and share alike? Gender-pairing, personality, and cognitive ability as determinants of giving. Journal of Economic Psychology, 25, 581-589. http://dx.doi.org/10.1016/S01674870(03)00065-5 
Ben-Ner, A., \& Kramer, A. (2011). Personality and altruism in the dictator game: Relationship to giving to kin, collaborators, competitors, and neutrals. Personality and Individual Differences, 52, 216-221.

http://dx.doi.org/10.1016/j.paid.2010.04.024

Bickhoff, L., Sinclair, P. M., \& Levett-Jones, T. (2015). Moral courage in undergraduate nursing students: A literature review. Collegian: The Australian Journal of Nursing Practice, Scholarship and Research. Advance online publication. http://dx.doi.org/10.1016/j.colegn.2015.08.002

Bilsky, W., \& Schwartz, S. H. (1994). Values and personality. European Journal of Personality, 8, 163-181. http://dx.doi.org/10.1002/per.2410080303

Blaszczynski, A., Gainsbury, S., \& Karlov, L. (2014). Blue Gum gaming machine: An evaluation of responsible gambling features. Journal of Gambling Studies, 30, 697-712. http://dx.doi.org/10.1007/s10899-013-9378-5

Böckler, A., Sharifi, M., Kanske, P., Dziobek, I., \& Singer, T. (2017). Social decision making in narcissism: Reduced generosity and increased retaliation are driven by alterations in perspective-taking and anger. Personality and Individual Differences,104. Advance online publication. http://dx.doi.org/10.1016/j.paid.2016.07.020

Buckels, E. E., \& Paulhus, D. L. (2013). Comprehensive assessment of sadistic tendencies (CAST). Unpublished measure, University of British Columbia. Retrieved from:

http://www.academia.edu/3684242/Comprehensive_Assessment_of_Sadistic_Tendencies_Cast_

Buckels, E. E., Trapnell, P. D., \& Paulhus, D. L. (2014). Trolls just want to have fun. Personality and Individual Differences, 67, 97-102. http://dx.doi.org/10.1016/j.paid.2014.01.016

Calvete, E., Orue, I., Estévez, A., Villardón, L., \& Padilla, P. (2010). Cyberbullying in adolescents: Modalities and aggressors' profiles. Computers in Human Behavior, 26, 1128-1135. http://dx.doi.org/10.1016/j.chb.2010.03.017

Carlo, G., Okun, M. A., Knight, G. P., \& de Guzman, M. R. T. (2005). The interplay of traits and motives on volunteering: Agreeableness, extraversion and prosocial value motivation. Personality and Individual Differences, 38, 1293-1305. http://dx.doi.org/10.1016/j.paid.2004.08.012

Correa, T., Hinsley, A. W., \& de Zúñiga, H. G. (2010). Who interacts on the Web?: The intersection of users' personality and social media use. Computers in Human Behavior, 26, 247-253.

http://dx.doi.org/10.1016/j.chb.2009.09.003

Dawes, C. T., Fowler, J. H., Johnson, T., McElreath, R, \& Smirnov, O. (2007). Egalitarian motives in humans. Nature, 446, 794-797. http://dx.doi.org/10.1038/nature05651

Dickert, S., Sagara, N., \& Slovic, P. (2011). Affective motivations to help others: A two-stage model of donation decisions. Journal of Behavioral Decision Making, 24, 361-376. http://dx.doi.org/10.1002/bdm.697

Elshaug, C., \& Metzer, J. (2001). Personality attributes of volunteers and paid workers engaged in similar occupational tasks. Journal of Social Psychology, 141, 752-763. http://dx.doi.org/10.1080/00224540109600586

Greitemeyer, T. (2015). Everyday sadism predicts violent video game preferences. Personality and Individual Differences, 75, 19-23. http://dx.doi.org/10.1016/j.paid.2014.10.049

Halmburger, A., Baumert, A., \& Schmitt, M. (2015). Anger as driving factor of moral courage in comparison with guilt and global mood: A multimethod approach. European Journal of Social Psychology, 45, 39-51.

http://dx.doi.org/10.1002/ejsp.2071

Hobfoll, S. E. (1980). Personal characteristics of the college volunteer. American Journal of Community Psychology, 8, 503-506. http://dx.doi.org/10.1007/BF00912860 
Hodson, G., Hogg, S. M., \& MacInnis, C. C. (2009). The role of "dark personalities" (narcissism, Machiavellianism, psychopathy), Big Five personality factors, and ideology in explaining prejudice. Journal of Research in Personality, 43, 686-690. http://dx.doi.org/10.1016/j.jrp.2009.02.005

Jackson, J. W., \& Poulsen, J. R. (2005). Contact experiences mediate the relationship between five-factor model personality traits and ethnic prejudice. Journal of Applied Social Psychology, 35, 667-685.

http://dx.doi.org/10.1111/j.1559-1816.2005.tb02140.x

John, O. P., Naumann, L. P., \& Soto, C. J. (2008). Paradigm shift to the integrative big five trait taxonomy. In O. P. John, R. W. Robins, \& L. A. Pervin (Eds.), Handbook of personality: Theory and research (pp. 114-158). New York, NY: The Guilford Press.

Kayser, D. N., Greitemeyer, T., Fischer, P., \& Frey, D. (2010). Why mood affects help giving, but not moral courage: Comparing two types of prosocial behavior. European Journal of Social Psychology, 40, 1136-1157.

http://dx.doi.org/10.1002/ejsp.717

Kinnunen, S. P., Singh, M., \& Windmann, S. (2015). Dissociating facets of self-reported altruism in India and Germany: Preliminary evidence. Psychological Studies, 60, 193-203. http://dx.doi.org/10.1007/s12646-015-0309-7

Kinnunen, S. P., \& Windmann, S. (2013). Dual-processing altruism. Frontiers in Psychology, 4. http://dx.doi.org/10.3389/fpsyg.2013.00193

Klisanin, D. (2011). Is the Internet giving rise to new forms of altruism? Media Psychology Review, 3, 1. Retrieved from http://mprcenter.org/review/internetdigitalaltruism/

Konstabel, K., Lönnqvist, J.-E., Walkowitz, G., Konstabel, K., \& Verkasalo, M. (2012). The 'Short Five' (S5): Measuring personality traits using comprehensive single items. European Journal of Personality, 26, 13-29.

http://dx.doi.org/10.1002/per.813

Krueger, R. F., Hicks, B. M., \& McGue, M. (2001). Altruism and antisocial behavior: Independent tendencies, unique personality correlates, distinct etiologies. Psychological Science, 12, 397-402.

http://dx.doi.org/10.1111/1467-9280.00373

Kruger, J., Epley, N., Parker, J., \& Ng, Z.-W. (2005). Egocentrism over e-mail: Can we communicate as well as we think? Journal of Personality and Social Psychology, 89, 925-936. http://dx.doi.org/10.1037/0022-3514.89.6.925

Latané, B., \& Darley, J. M. (1968). Group inhibition of bystander intervention in emergencies. Journal of Personality and Social Psychology, 10, 215-221. http://dx.doi.org/10.1037/h0026570

Lodge, J., \& Frydenberg, E. (2005). The role of peer bystanders in school bullying: Positive steps toward promoting peaceful schools. Theory into Practice, 44, 329-336. http://dx.doi.org/10.1207/s15430421tip4404_6

McCrae, R. R., \& Costa, P. T., Jr. (2003). Personality in adulthood: A Five-Factor Theory perspective. New York, NY: Guilford Press.

Myers, W. C., Burket, R. C., \& Husted, D. S. (2006). Sadistic personality disorder and comorbid mental illness in adolescent psychiatric inpatients. Journal of the American Academy of Psychiatry and the Law Online, 34, 61-71.

Parks-Leduc, L., Feldman, G., \& Bardi, A. (2014). Personality traits and personal values: A meta-analysis.

Personality and Social Psychology Review, 19, 3-29. http://dx.doi.org/10.1177/1088868314538548

Patchin, J. W., \& Hinduja, S. (2006). Bullies move beyond the schoolyard: A preliminary look at cyberbullying. Youth Violence and Juvenile Justice, 4, 148-169. http://dx.doi.org/10.1177/1541204006286288 
Poteat, V. P., \& Vecho, O. (2016). Who intervenes against homophobic behavior? Attributes that distinguish active bystanders. Journal of School Psychology, 54, 17-28. http://dx.doi.org/10.1016/j.jsp.2015.10.002

Pöyhönen, V., Juvonen, J., \& Salmivalli, C. (2012). Standing up for a victim, siding with the bully, or standing by? Bystander responses in bullying situations. Social Development, 21, 722-741. http://dx.doi.org/10.1111/j.14679507.2012.00662.x

Rigby, K., \& Smith, P. K. (2011). Is school bullying really on the rise? Social Psychology of Education, 14, 441-455. http://dx.doi.org/10.1007/s11218-011-9158-y

Roccas, S., Sagiv, L., Schwartz, S. H., \& Knafo, A. (2002). The Big Five personality factors and personal values. Personality and Social Psychology Bulletin, 28, 789-801. http://dx.doi.org/10.1177/0146167202289008

Rudolph, U., Roesch, S., Greitemeyer, T., \& Weiner, B. (2004). A meta-analytic review of help giving and aggression from an attributional perspective: Contributions to a general theory of motivation. Cognition and Emotion, 18, 815-848. http://dx.doi.org/10.1080/02699930341000248

Rushton, J. P., Chrisjohn, R. D., \& Fekken, G. C. (1981). The altruistic personality and the self-report altruism scale. Personality and Individual Differences, 2, 293-302. http://dx.doi.org/10.1016/0191-8869(81)90084-2

Sagiv, L., Sverdlik, N., \& Schwarz, N. (2011). To compete or to cooperate? Values' impact on perception and action in social dilemma games. European Journal of Social Psychology, 41, 64-77. http://dx.doi.org/10.1002/ejsp.729

Schwartz, S. H. (1992). Universals in the content and structure of values: Theoretical advances and empirical tests in 20 countries. Advances in Experimental Social Psychology 25, 1-65. http://dx.doi.org/10.1016/S0065-

2601(08)60281-6

Schwartz, S. H. (2010). Basic values: How they motivate and inhibit prosocial behavior. In M. Mikulincer \& P. R. Shaver (Eds.), Prosocial motives, emotions, and behavior: The better angels of our nature (pp. 221-241). Washington, DC: American Psychological Association.

Schwartz, S. H., \& Bilsky, W. (1990). Toward a theory of the universal content and structure of values: Extensions and cross-cultural replications. Journal of Personality and Social Psychology, 58, 878-891.

http://dx.doi.org/10.1037/0022-3514.58.5.878

Schwartz, S. H., Melech, G., Lehmann, A., Burgess, S., Harris, M., \& Owens, V. (2001). Extending the cross-cultural validity of the theory of basic human values with a different method of measurement. Journal of Cross-Cultural Psychology, 32, 519-542. http://dx.doi.org/10.1177/0022022101032005001

Sekerka, L. E., Bagozzi, R. P., \& Charnigo, R. (2009). Facing ethical challenges in the workplace: Conceptualizing and measuring professional moral courage. Journal of Business Ethics, 89, 565-579.

http://dx.doi.org/10.1007/s10551-008-0017-5

Stel, M., Van Baaren, R. B., \& Vonk, R. (2008). Effects of mimicking: Acting prosocially by being emotionally moved. European Journal of Social Psychology, 38, 965-976. http://dx.doi.org/10.1002/ejsp.472

Sticca, F., \& Perren, S. (2013). Is cyberbullying worse than traditional bullying? Examining the differential roles of medium, publicity, and anonymity for the perceived severity of bullying. Journal of Youth and Adolescence, 42, 739-750. http://dx.doi.org/10.1007/s10964-012-9867-3

Thornberg, R. (2007). A classmate in distress: Schoolchildren as bystanders and their reasons for how they act. Social Psychology of Education, 10, 5-28. http://dx.doi.org/10.1007/s11218-006-9009-4

Utz, S. (2009). Egoboo vs. altruism: The role of consumer reputation in online consumer communities. New Media \& Society, 11, 357-374. http://dx.doi.org/10.1177/1461444808101616 
Verkasalo, M., Lönnqvist, J.-E., Lipsanen, J., \& Helkama, K. (2009). European norms and equations for a two dimensional presentation of values as measured with Schwartz's 21 -item Portrait Values Questionnaire. European Journal of Social Psychology, 39, 780-792. http://dx.doi.org/10.1002/ejsp.580

Wang, C. C., \& Wang, C. H. (2008). Helping others in online games: Prosocial behavior in cyberspace. CyberPsychology \& Behavior, 11, 344-346. http://dx.doi.org/10.1089/cpb.2007.0045

Weinstein, N., \& Ryan, R. M. (2010). When helping helps: Autonomous motivation for prosocial behavior and its influence on well-being for the helper and recipient. Journal of Personality and Social Psychology, 98, 222-244. http://dx.doi.org/10.1037/a0016984

Winter, D. G., John, O. O., Stewart, A. J., Klohnen, E. C., \& Duncan, L. E. (1998). Traits and motives: Toward an integration of two traditions in personality research. Psychological Review, 105, 230-250.

http://dx.doi.org/10.1037/0033-295X.105.2.230

Wright, M. F., \& Li, Y. (2011). The associations between young adults' face-to-face prosocial behaviors and their online prosocial behaviors. Computers in Human Behavior, 27, 1959-1962.

http://dx.doi.org/10.1016/j.chb.2011.04.019

\section{Correspondence to:}

Suna Kinnunen

Institute of Behavioural Sciences

P.O. Box 9

$\mathrm{Fl}-00014$

University of Helsinki, Finland

Email: spkinnun(at)gmail.com

\section{About authors}

Suna Kinnunen is a PhD (psychology) from University of Frankfurt, Germany, and a MSc (computer science) from University of Jyväskylä, Finland. Her research interests include prosocial behavior, information security, social engineering, memory, and child development.

Marjaana Lindeman (PhD) is the principal researcher of Research on Everyday Thinking group, Division of Cognitive Psychology and Neuropsychology, University of Helsinki, Finland. Her research interests include the belief in supernatural and underlying cognition, and intuitive and analytical thinking.

Markku Verkasalo (PhD) is the head of the Self Presentation and Values research group at the University of Helsinki. 